\title{
A semantic and pragmatic approach to verb particle constructions used in cartoons and puns
}

\author{
Abdeljalil Naoui Khir \\ naouikhira@vmi.edu \\ Virginia Military Institute, USA
}

\begin{abstract}
The aim of this paper is to discuss a special type of verb particle construction in English; namely, phrasal verbs used in cartoons and puns. Granted that the meaning of phrasal verbs may range from literal to idiomatic, their use in cartoons is artistically and linguistically exploited through a combination of verbal and non-verbal cues to convey humor, satire and fun. Our assumption is that this combination rests on the premise that a double reading of phrasal verbs in certain cartoons and puns is possible. To illustrate this, a sample of cartoons using phrasal verbs and puns (taken from www.ecenglish.com, English Teacher Online $L L C$ ) will be analyzed showing how the correspondence between the cartoon as a visual mode and the phrasal verb as a linguistic form can yield both literal interpretations and idiomatic ones. Phrasal verbs are also shown to violate Gricean maxims and to depend largely, in their interpretation, on extra linguistic factors.
\end{abstract}

Keywords: cartoons, puns, phrasal verbs, Gricean maxims, (un)marked

\section{INTRODUCTION}

There is an extensive body of literature dealing with phrasal verbs. Moreover, the manifold approaches towards such constructions seem to be controversial. Yet, it must be pointed out that in the treatment of phrasal verbs two major points should be stressed: 1) the problem related to their grammatical status and 2) The problem of their idiomaticity.

Some ${ }^{1}$ consider that phrasal verbs are very different from verbs with prepositions both semantically and syntactically'. They see that in phrasal verbs the particle is intrinsically connected to the verb to form a single semantic unit. With verbs followed by prepositions, the preposition is part of a prepositional phrase and does not change the

\footnotetext{
${ }^{1}$ See Leila Ranta's 2008 article "Figuring Out Phrasal Verbs: Practical Ideas from Research" where she states that "Many ESL textbooks make no distinction between phrasal and prepositional verbs calling them both 'phrasal verbs'. Unfortunately, this simplification may lead to greater confusion in the long run because phrasal and prepositional verbs have different characteristics” p. 1. And for a more elaborate and detailed discussion see Biber et al. 1999; especially Section 5 on multi-word lexical verbs pp.360-402, and section 13 on idiomatic phrases and free combinations pp. 990- 1028.
} 
meaning of the verb. Others ${ }^{2}$, however, include both the adverb and the preposition as constituents of a phrasal verb.

If some linguists disagree on what elements constitute a phrasal verb, what they seem to disagree more about is whether to include those constructions having a literal meaning within the sphere of phrasal verbs or to consider them otherwise.

They have adopted two main positions with regard to the nature and use of phrasal verbs:

They see that the literal use of a form like lift up, put down and a host of others do not constitute a phrasal verb as such, but a verb operating with a particle and that the term phrasal verb should properly be reserved for figurative and idiomatic uses (Cf. Martha J. Kolln, and Robert W. Funk 2008: 35). ${ }^{3}$ Others would consider that phrasal verbs may range from totally transparent to totally opaque. (Cf. McArthur 1992: 773).

Our aim in this paper is not to examine the problems in detail or to review the literature. Since this paper is concerned primarily with phrasal verbs used in cartoons and not with the theoretical aspects of phrasal verbs, our discussion will thus be related only to a clarification of points and concepts required for an understanding of the topic. We shall, therefore, focus on relevant points and mainly the transparency and idiomaticity of phrasal verbs and the role that contextual factors can play. Let us begin by the first element, the label phrasal verbs. For us, this term covers both the literal and figurative/idiomatic uses, and therefore includes syntax, morphology, and semantics.

Based on their approach, linguists refer to the combination of a basic verb and another word or words by using various labels, the most widely used of which is phrasal verb, the term we will be using in our analysis. Other labels used are compound verbs, verbadverb combinations, verb-particle constructions (VPCs), or two-part verbs and threepart verbs (depending on the number of particles used). ${ }^{4}$

It is also commonly thought that almost every phrasal verb has a corresponding equivalent single verb. For example, search could be used instead of look for, as could

\footnotetext{
${ }^{2}$ Cf. McArthur, T. (1992) The Oxford Companion to the English Language. Oxford University Press.

${ }^{3}$ Martha Kolln and Robert Funk (2008: 35) suggested that "phrasal verbs define only those combinations that form an idiom, a phrase whose meaning cannot be predicted from the meaning of its parts.”

${ }^{4}$ Cf. McArthur (1992:pp.72-76)
} 
extinguish be used instead of put out and continue as an equivalent to carry on and the list of examples is long. However, the status assigned to phrasal verbs is somewhat prejudiced: they are said to be “informal, emotive and slangy” (McArthur 1992: 774), and are "extremely common, especially in spoken English. They are used more informally than their Latinate synonyms”.

Fletcher (2005: 11) considers this to be an oversimplification and he considers that phrasal verbs, (which he calls Multiple Word Verbs)

are used across all types of text, even when the writer or speaker has the option of choosing a single-word alternative. They tend to enter the language through casual speech, but gradually become accepted across a wider range of texts, reaching even the most technical or conservative text types.

Dwight Bolinger (1971) also notes that phrasal verbs are more expressive than the synonyms they replace. He contrasts insult with jump on; exult with jump up and down with joy; and assault with jump at (Cf. also Claridge ${ }^{5}$ 2000, quoted in Lary Ceplair 2008, for a similar point).

It is not really true anymore to say that a phrasal verb always has a formal equivalent. The form you use or choose often depends on the context. There are now many phrasal verbs such as check in, plug in or log on that have come into English over the last years from science, technology and computing and they are known to have no alternative forms expressed in simple verbs. So when you use any of these phrasal verbs above you are not using a slang word that should be replaced by a formal verb since the phrasal verb is the only way of describing these actions.

Hence, it is simply not true to say that phrasal verbs are always slang and poor-quality English, since, as shown above, they may be the only way to express an idea. A wide range of phrasal verbs are metaphorical and ambivalent and therefore prone to diverse interpretations, which makes them more appropriate and playful in particular contexts and situations, as in jokes and cartoons.

\footnotetext{
${ }^{5}$ In her article "Multi-Word Verbs in Early Modern English" (2000), quoted in Larry Ceplair 2008, Claudia Claridge cites several phonic and syntactical reasons for the shift from single verbs to phrasal verbs. First, there was the lack of a fitting, one-word synonym for the thought to be expressed.: "Take advantage of" by "exploit”; "find fault with" by "criticize"; "fall short of" by "fail”; and "lay about" by "loll". Second, phrasal verbs are more precise and to the point. Her third reason is that phrasal verbs provide additional meaning. And her fourth reason is that phrasal verbs are more expressive, emphatic, playful, and metaphorical.
} 
Phrasal verbs may range from totally transparent constructions to totally opaque ones with those at the opaque end of the scale as pure idiomatic phrasal verbs. The categorization of phrasal verbs as transparent or opaque depends on the contribution of the verb and particle to the overall meaning. When both of these keep their original concrete meaning, the phrasal verb is considered literal (Frazer 1976). If it is only the verb that retains its original meaning, however, it is then called semi-idiomatic (Spasov 1966). Finally, when neither verb nor particle keep their basic meaning, and a new meaning is assigned to the combined elements of the phrasal verb, it is known as idiomatic.

A different categorization also based on the combination and contribution of verb and particle yields four categories rather than just three. This alternative way of classifying such elements was suggested by Bannard et al. (2003), and quoted in Patrick and Fletcher (2006: 6), who see that phrasal verbs "can be sub-classified into four compositionality classes based on the independent semantic contribution of the verb and particle”. They roughly categorize them in the following way (examples from Barnard et al. 2003):

(1) Both the verb and particle contribute semantically. For example, Peter put the picture up.

(2) Only the verb contributes semantically. For example, Susan finished up her paper.

(3) Only the particle contributes semantically, as when you say: the thief made away with the case.

(4) Neither the verb nor the particle contributes semantically. For example, Barbara and Simon made out.

Yet, the problem with these categorizations is that idiomaticity in phrasal verbs is more complex than that. Quite often, one and the same phrasal verb may have both a literal and a figurative meaning, depending on context, as the following examples can show: 


\section{Literal meaning}

She put down the book

She looked into a mirror

They live on the fourth floor.

\section{Figurative meaning}

The army could not put down the rebellion in Libya.

We will look into the problem together.

They are poor and live on rice and beans.

Ambivalence is another characteristic of phrasal verbs. Some may have a wide range of different meanings depending on their use in the context. One notorious example is the phrasal verb pick up, which is frequently listed with around 20 different meanings in dictionaries: (understand/comprehend, retrieve from the ground, etc.). So it seems that the variety of meanings of a phrasal verb has more to do with contextual factors than with the construction itself.

How can we then draw a line between literal and figurative/ idiomatic uses of phrasal verbs and is it possible to do so? The answer seems to be far from positive because, as shown above, the same phrasal verb may have multiple meanings and may once be used literally and on other occasions metaphorically or idiomatically. Another reason is to be found in the semantic meaning of the parts that constitute the phrasal verb (verb + particle) and their contribution to the overall meaning (Barnard et al. 2003). Other contextual factors may also be involved when uttering the phrasal verb, as in cases of irony, jokes and cartoons.

This continuum from literal (transparent) to idiomatic (opaque) illustrated in the phrasal verbs above and the multiplicity of meanings of one and the same phrasal verb make them an interesting linguistic phenomenon. Phrasal verbs are exploited in diverse domains of language use, mainly in advertising and cartoons to convey double messages. For example, the phrasal verb "You can count on us" used to advertize calculators shows that this phrase could be interpreted literally and/or metaphorically. Also in cartoons a double message is conveyed through the visual image presented through caricature and the linguistic message presented in the caption accompanying the cartoon. Let us then see how these are illustrated in cartoons. 


\section{PHRASAL VERBS IN CARTOONS}

In cartoons, meaning is conveyed through the verbal and the visual. Due to this interaction between what is said and what is seen, between language and image, attention should be paid to the visual message and to exaggeration, contradiction, and metaphor as mechanisms to create humor.

Cartoons, like jokes, are often based on a deliberate confusion of phrasal-verb meanings. They are widely used as a means of social satire to comment on political events, domestic or family matters, and undesirable behaviors such as cheating and immorality.

Phrasal verbs can also be used to enhance teaching. Among the possible reasons for using cartoons as authentic material in teaching, one can cite the following:

Since phrasal verbs are highly used in informal situations by native speakers, their teaching/ learning through the visual context of cartoons would allow teacher and students to deal with them easily as they are used to represent concrete and authentic situations. Consequently, students would comprehend them better and could use them in real-to-life situations with much ease. Also, given that cartoons are usually humorous, dealing with them in such contexts would surely make learning fun and would help and stimulate students to learn. The visual context within which phrasal verbs appear in cartoons would probably help students to memorize and recall such structures better than when they are merely presented as lists. Additionally, cartoons, in general, thanks to their visual property, illustrate aspects of culture and values of the targeted people and language (the way people are clad, proximity and many other non-linguistic features). Another important component that cartoons as visuals can provide is their ability to show non-verbal aspects of communication: facial expressions, body postures and relevant gestures. All these can be exploited along with the linguistic components and can help students develop an accurate communicative competence. The phrasal verbs used in cartoons in this paper can help students perceive the ambiguity and contrast between the literal and metaphorical uses of phrasal verbs and in what situations they are appropriately used. Some other possible ways of how to use them in teaching is to elicit the possible meaning of a phrasal verb based on the visual information in the cartoon, and if used for a review, to ask the students to match non- 
captioned cartoons with the phrasal verbs that would go with them. Obviously, the choice of the cartoon and the phrasal verb should match the level of the students and the targeted skill(s).

The samples of cartoons discussed in this paper represent a clash between the conventional/metaphorical and/or idiomatic meaning of a phrasal verb and the meaning provided by the visual information in the cartoon, which is a literal one. Students with an advanced level could be taught or asked to detect such a difference based on the information of what is linguistically said in the phrasal verb and the plausibility of what is illustrated or inferred from the message/illustration in the cartoon. For example, situation number one, where in the cartoon a policeman is shown as physically holding a car in his hand, is implausible. Therefore, it is not a likely expected interpretation of the phrasal verb, but one that is meant to be a joke since, in this case, it is taken literally. This will help students develop their competencies to understand literal and metaphorical uses of language thanks to the context of use of phrasal verbs and the extra linguistic context provided by cartoons.

Humor is of paramount importance to cartoons, and both the verbal and the visual cues in cartoons are fertile grounds for such humor. Cartoons also materialize conceptual metaphors.

To illustrate this, I have selected instances of phrasal verbs used in cartoons and puns taken from the web site www.ecenglish.com and English Teacher Online LLC, respectively. 
Situation 1: "Hold up"

Copyright $\mathbb{C}^{\text {www.ecenglish.com }}$

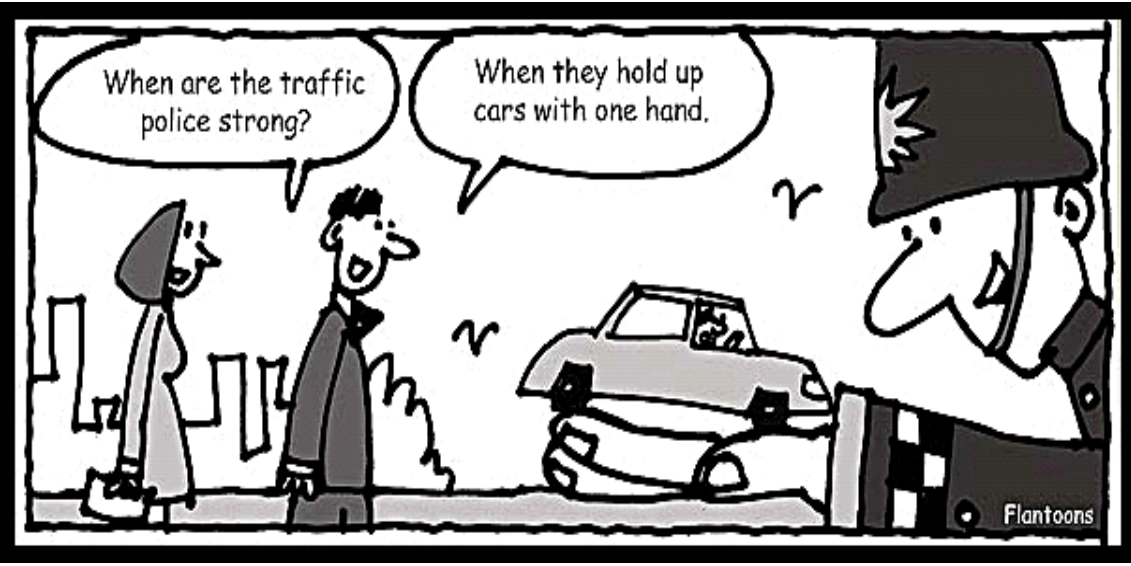

In the interaction of this cartoon (situation 1) a question is posed asking about when traffic police are strong. The given reply "when they hold up cars with one hand" evokes two images: one based on our experience with traffic police, who with their authority can raise their hand as a signal for a driver to stop and the latter has to obey the traffic police (hence their authority). The second image is the 'distorted', funny image in the cartoon representing a policeman physically and literally holding a car in his hand (hence his physical strength). So, here, the cartoon enhances the literal meaning of the phrasal verb making the situation funny due to its unusualness.

\section{Situation 2: "Pick up"}

Copyright ${ }^{C}$ www.ecenglish.com

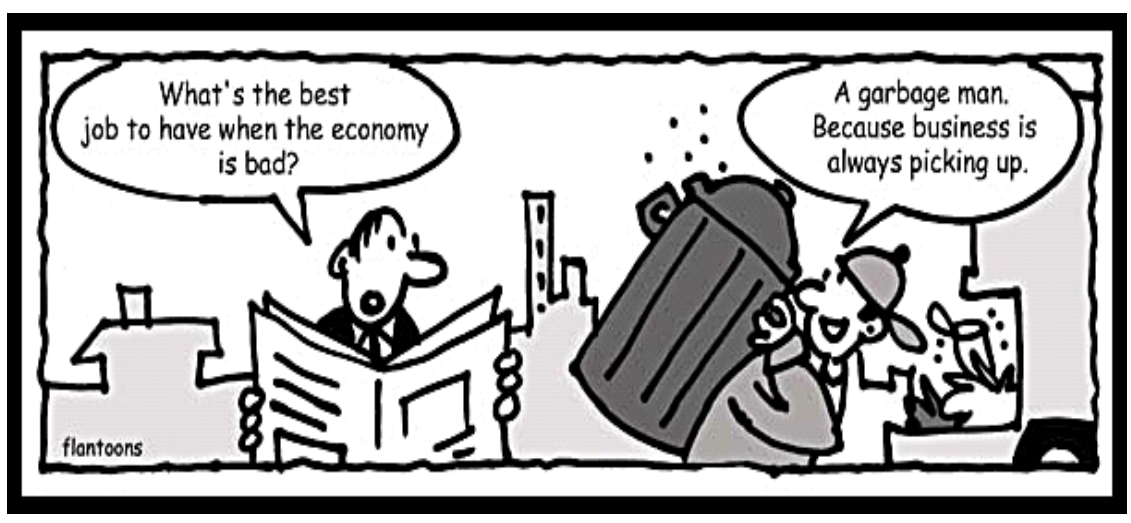


Here again we find that the question being asked is about the best job to have when the economy is bad. It is taken in a humorous way when the answer "pick up" does not refer, as we expect, to improvement of the bad situation (an idiomatic meaning). Rather, it refers to the literal meaning of "pick up" which is "lifting up" and this meaning is contrary to our expectations, but is supported by the image in the cartoon representing a man lifting up (raising from the ground) a garbage can.

\section{Situation 3: "Step on"}

Copyright $(\underset{\text { www.ecenglish.com }}{ }$

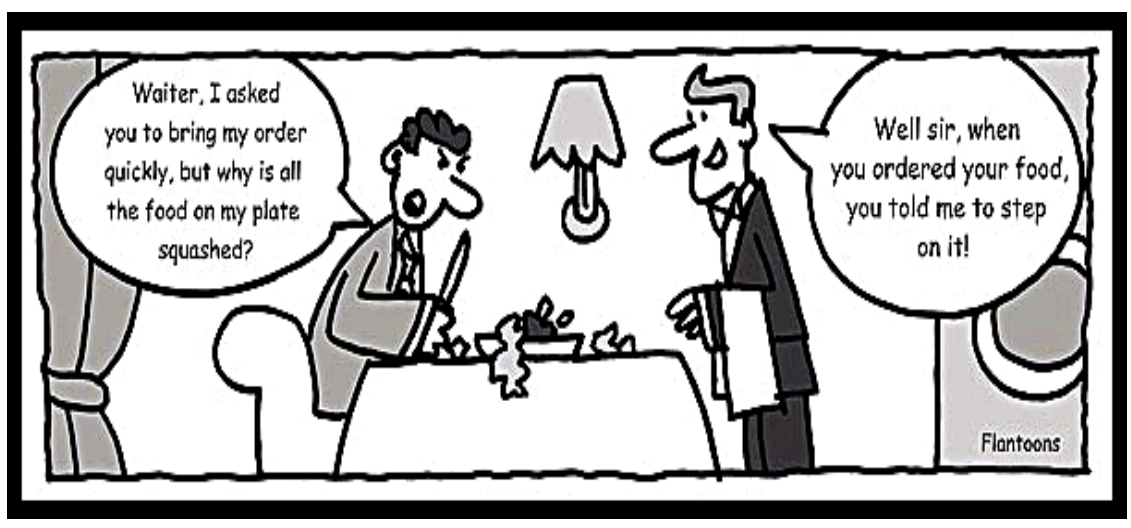

The customer's question "I asked you to bring my order quickly, but why is all the food on my plate squashed?”, is a reproach that is made clear by the juxtaposed statement emphasized by the use of the word 'but', as well as by the expression on his face, which is clearly depicted in the cartoon, and which shows the customer's anger. All these extra linguistic factors make it clear that the waiter misunderstood the meaning of "step on". His reply "Well sir, when you ordered your food, you told me to step on it" shows that he understood the phrasal verb literally and thus pressed his foot on the food rather than doing his best to bring it quickly. Once again, fun and humor are the result of taking the idiomatic phrasal verb literally. 


\section{Situation 4: "Put down"}

Copyright (C) www.ecenglish.com

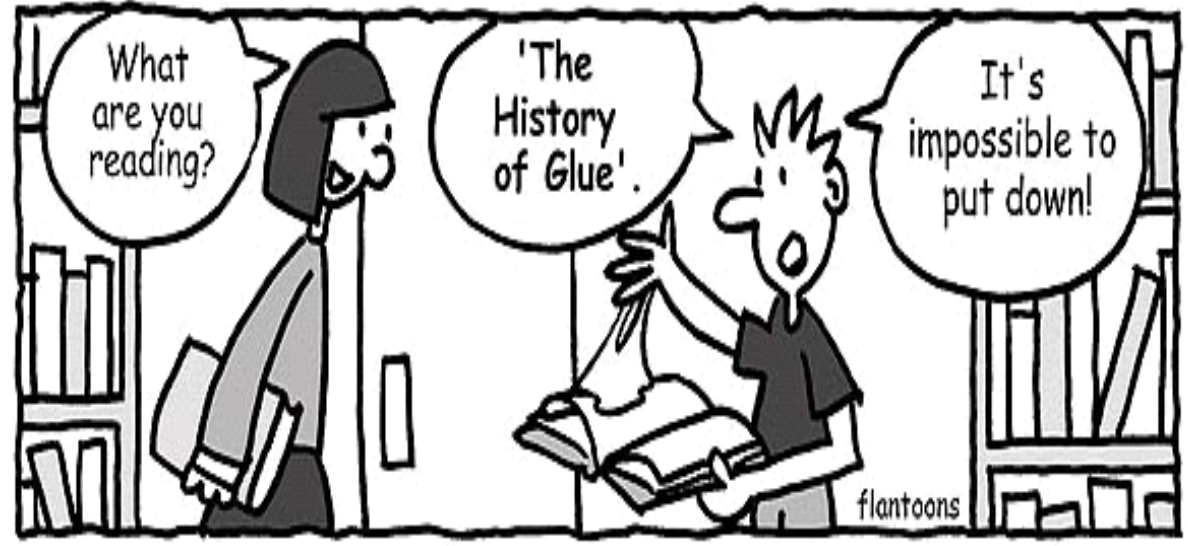

The phrasal verb "put down" is usually employed in the negative form and is commonly collocated with books or reading matter. So, to express that we get so engrossed with what we are reading that it was difficult to stop reading it, we usually say that it is so interesting that we cannot put it down. In the cartoon, the man's use of "glue" and the depicted image of the man's hand glued to the book both emphasize the literal interpretation "to physically stop holding what we have in our hand". Here again, from the visual elements in the cartoon, it becomes clear that the idiomatic phrasal verb has been interpreted literally. 
Situation 5: "Stand in the way"

Copyright (C) www.ecenglish.com

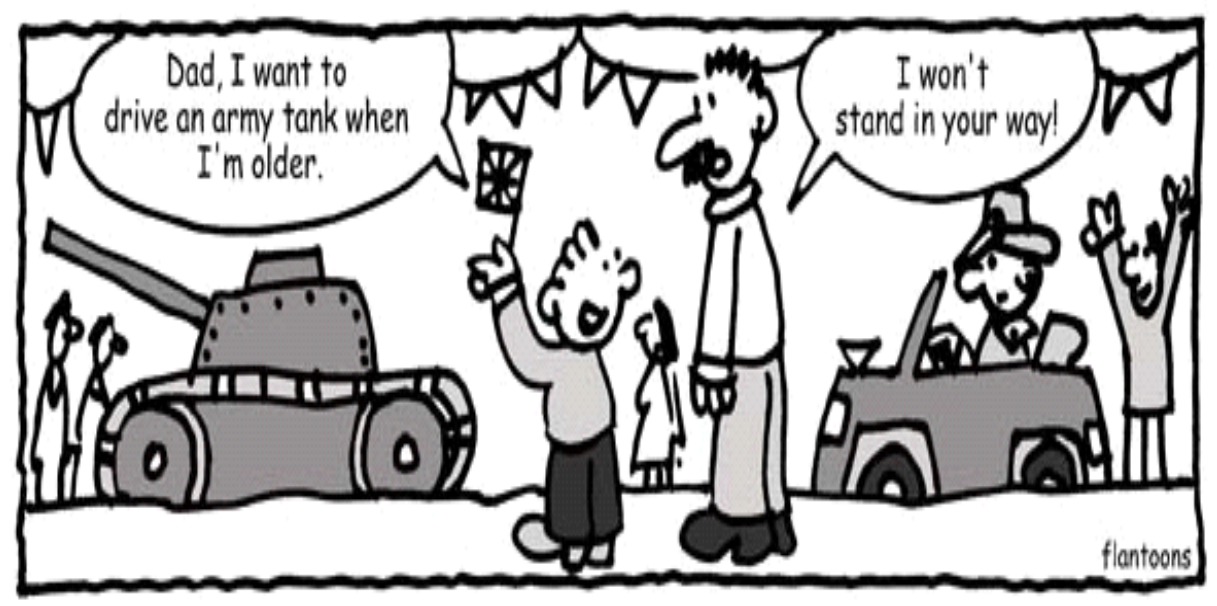

This phrasal verb has two basic interpretations: one purely literal in the sense that to stand in someone's way could mean to be placed physically as an obstacle in someone's pathway. So if you stand in my way, you prevent me from moving past you or getting through somewhere. The other meaning is metaphorical and refers to preventing an event from happening, such as attempting to prevent someone's plans from taking place by refusing or causing problems. Based on the information in the cartoon and since it is a child who expresses his future desire to drive an army tank, the father's statement sounds more of a self-assurance than a promise not to intervene with the child's wish. What also emphasizes this idea is the presence of extra linguistic factors; namely, the physical presence of individuals in the cartoon portrayed as standing in front of vehicles: a car and a tank. The purpose is to emphasize the literal meaning. 
Situation 6: "See through"

Copyright $(\underset{\text { www.ecenglish.com }}{ }$

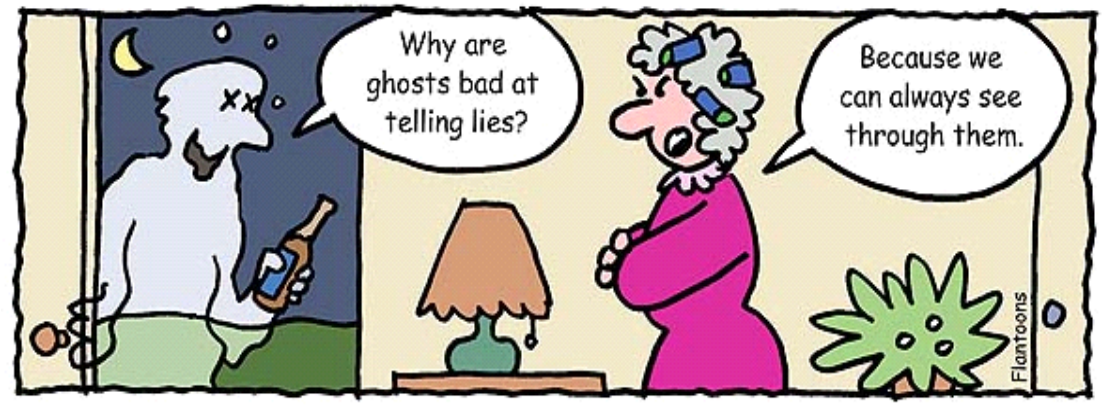

In this cartoon, there is a picture of a woman and a ghost. They are depicted as having a conversation. Ghosts are assumed to be transparent so that we can see through them. Therefore nothing on the other side can be hidden. We can see through ghosts, fake things and lies, just as we can see what is on the other side of a piece of glass by looking through it. Hence the woman's statement “We can see through them”, refers to being able to detect a lie when we hear one because it is poorly disguised: the pun revolves around "them" in this case because, depending on whether we choose to interpret it as "ghosts" or "lies", we interpret the phrasal verb accordingly.

Because such cartoons seem to show exactly what those phrasal verbs literally say, not what they metaphorically mean, and because such an interpretation is implausible, they create fun and humor. Humor is pragmatically the result of a violation of our expectation of how the real world is. The depiction of a policeman holding a car (situation 1) or a waiter stepping on food (situation 3) is incompatible with our knowledge of the real world just as any other humorous situation may be. Thus, a comprehensive understanding of phrasal verbs in cartoons as those illustrated above necessitates a consideration of what is linguistically said, and what is illustrated: the visual context. When these two are put together, we have a combination of the linguistic context, which is the phrasal verb with its syntactic form and its conventional or metaphorical meaning, and the presence of an unexpected or forced literal meaning brought forth in the cartoon. 
Another means of humor is the use of puns. A pun is defined as:

"a humorous use of a word in such a way as to suggest two or more of its meanings or the meaning of another word similar in sound" (source: Merriam Webster's dictionary online: http://www.meriam-webster.com/dictionary/pun ).

Humor here is based on the wrong assumption that sounding alike means being alike. A combination of puns and cartoons is possible as the following example can illustrate:

\section{Situation 7: “Go on strike”}

Copyright (C) 2010 English Teacher Online LLC.

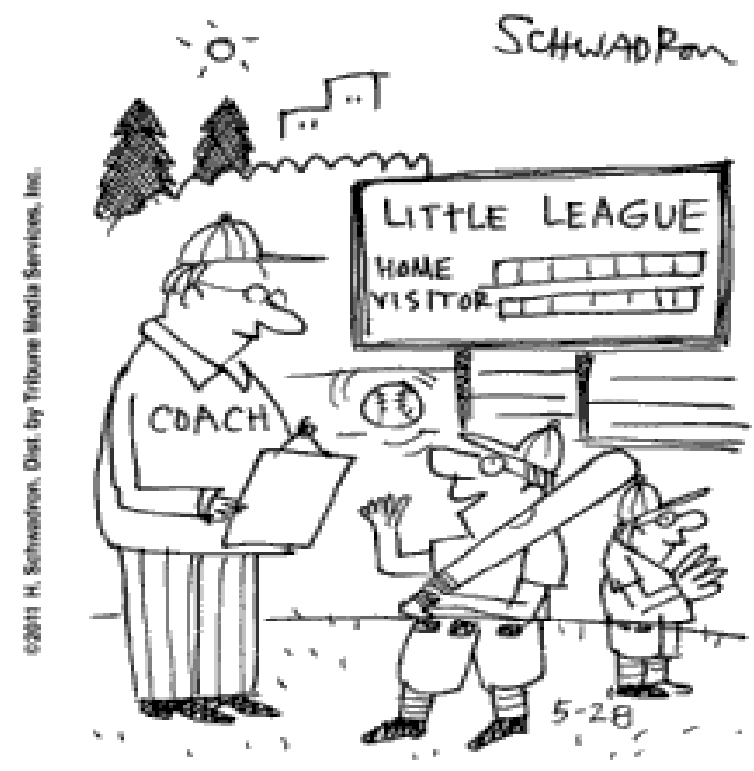

"When do we learn how to go on strike?"

"To go on strike" is employed to make a pun in this example where a young baseball player is depicted as addressing the question to his coach, asking him "When do we learn how to go on strike?" thereby evoking two different meanings: On the one hand, a strike in baseball results when a batter:

a) swings at and misses a pitch,

b) doesn't swing at a pitch in the strike zone or

c) hits a foul ball that is not caught 
(Source: Online Sports Dictionary: SportsDefinitions.com http://www.sportsdefinitions.com/baseball/strike.htlm)

On the other hand, "to go on strike" is "a period of time when workers stop work in order to force an employer to agree to their demands" (source: Merriam Webster's Learner's Dictionary http://www.learnersdictionary.com/com/search/strike2).

Obviously, without the visual presentation depicted in the cartoon, which evokes the meaning associated with a strike in baseball, the linguistic message ( the caption) would hardly yield a double meaning and so, no pun would take place in this case mainly because of the nature of the structure "to go on strike", which is idiomatic.

This double interpretation in each of these cartoons leading to fun and humor is due to the use of phrasal verbs which can have more than one interpretation and to the contribution of the image(s) in the cartoon. Yet, it is the visual content of the cartoon which conveys humor and fun. Many comic situations conveyed by cartoons owe their capacity to amuse more to the visual context in which they appear than to purely linguistic reasons. The phrasal verbs above used in cartoons would, out of that specific context, be most likely interpreted in their metaphorical or idiomatic meanings.

Although phrasal verbs are ambivalent and sometimes have multiple meanings to the extent that they can be used literally or metaphorically, they usually have a primary conventional meaning. This meaning can be the literal one or the metaphorical / idiomatic one. So, to say that traffic police can hold up cars, or that with certain jobs business is always picking up when the economy is bad, or to order someone to bring food and to step on it, or it's impossible to put down a book you are reading, etc. outside the cartoon context would hardly make you think of another interpretation than the one these phrasal verbs are usually associated with, namely, their primary conventional meaning. The role of the cartoons is to exploit these phrasal verbs with their metaphorical or idiomatic meanings and to use them in a context where a literal interpretation is made possible. This is in a sense just like when in conversation people use utterances in an indirect way only to find out that their addressees take them literally, that is, as direct speech acts. For example, if, to the conventional indirect request “Can you pass the salt?”, you get no compliance or action, but a mere response 
of the type "Sure, I can", you realize that your addressee is interpreting a request for action as if it were a mere question asking for information, just as anyone would use an idiom or metaphorical phrasal verb with its literal interpretation.

The questions concerning why phrasal verbs are exploited in this fashion in cartoons and why a metaphorical or idiomatic meaning is used to convey a literal meaning arise naturally at this point. A possible answer to these questions may be that phrasal verbs, in general, with sufficient context, can convey a literal interpretation even when their primary meaning is metaphorical or idiomatic. It is basically almost always possible to twist the meaning of an utterance that is taken as non-literal-metaphorical or idiomatic, and make it sound literal. Only, in doing so, fun or humor may be intended, and it becomes more striking, more humorous and more common if it is enhanced by its use within the framework of a cartoon.

Second, cartoons are used, regardless of their domain of use, to make fun, to entertain and even to criticise. To do so, they have to alter reality or exaggerate it. This is why a lot of caricature is used in cartoons.

Finally, cartoons allow us to use our imagination and to think of alternative views and interpretations of what we see, read or even know.

\section{GRICE'S COOPERATIVE PRINCIPLES AND MAXIMS}

Grice (1975) saw that conversation held between people is based on a shared principle of cooperation. He formulated it in the following way: "Make your contribution such as is required, at the stage at which it occurs, by the accepted purpose or direction of the talk exchange in which you are engaged.”

The Cooperative Principle is intended as a description of how people normally behave in conversation. Observing it serves to enhance effective communication. It consists of four maxims, which should be taken as assumptions about the way people will talk, rather than prescriptions for how they ought to talk. When these maxims are violated, people make inferences which Grice called implicatures.

Conversationalists can assume that when speakers intentionally flout a maxim, they do so with the aim of expressing some thought or idea. Thus, the Gricean maxims serve a 
purpose both when they are followed and even when they are flouted. Speakers who deliberately flout the maxims usually do so with the intention of getting their listener(s) to understand their underlying implication(s). The Gricean maxims are therefore often purposefully flouted by comedians and writers as well as by cartoonists, who may use linguistic devices such as metaphor, irony and puns, and manipulate their words for specific effects, depending on their readers or audience. Seana Coulson (in print) says in this respect:

(t)he cartoon presents itself as a puzzle for the viewer to solve. The challenge, it seems, is to activate the appropriate information in response to the imagery and the verbal cues, and to integrate it with abstract narrative structure....Because the cartoonist must provide the viewer with just enough information to reconstitute the input spaces, humorous examples necessarily depend on viewers having relevant knowledge and shared understandings about these domains.

Conversational implicatures are always indirect: we imply one thing by saying or communicating another. Cartoons using phrasal verbs work in this way. What is said has a meaning and what is implied has a different meaning when enhanced by the visual images in the cartoon.

Grice’s maxims and rules of conversation:

- Maxims of Quantity:

1. "Make your contribution as informative as is required" (for the current purposes of the exchange)

2. "Don’t make your contribution more informative than is required”

In other words, do not say more or less than what you should. Do not state the obvious.

- Maxims of Quality: Be truthful

1. "Don’t say what you believe to be false"

2. "Don’t say that for which you lack adequate evidence"

That is, do not lie or advocate what you are not sure about.

- Maxim of Relation:

"Be relevant" 
- Maxims of Manner: “Be perspicuous”

1. “Avoid obscurity of expression”

2. "Avoid ambiguity”

3. "Be brief (avoid unnecessary prolixity)”

4. "Be orderly"

In the cartoons above, there is, for each phrasal verb as a construction, a "logical"/ common interpretation and an "implied" one, that is to say, one that is specifically dependent and based on the visual context. For example, upon hearing me say "I really could not put down that book", the first thought you would have is the idiomatic meaning of my statement which amounts to saying "the book is so interesting that I cannot put it down". However, if I wanted to convey the literal interpretation of "I could not put it down" roughly meaning something like "I could not stop holding it, it has to be glued to my hand” (see cartoon above, situation 4) that would be a literal expression. In a similar way, the idiom "kick the bucket" would be highly likely to be interpreted as “die”. Yet, it is not impossible to use it literally and to mean 'hitting a bucket with one's foot' as in saying 'he kicked the bucket nervously and hurt his foot'. Here it is used literally and not as meaning "he died". Only context would make it clear which of the two interpretations is meant, though it is the conventional meaning that we think of first.

In terms of Grice's theory of conversation when people are interacting, they have expectations that amount to understanding and being understood. When someone asks you about the time, they expect you to tell them the time, but, of course, a different answer may be given for some reason. This different, unexpected answer is a breach, a violation of one of Grice's maxims. In our view, the use of phrasal verbs in cartoons in an ambiguous way with other possible interpretation(s) is also a violation of Grice's maxim. This other interpretation is supported by the image(s) in the cartoon: the visual context. For example, (see cartoon above, situation 5), the father's statement that he would not stand in the way of his child's wish to drive a tank may be ambiguous in the sense that the child understands it one way (idiomatically): that his father would not interfere and the father means another way (literally). This is a violation of the maxim of Manner, due to the ambiguity in the father's utterance. 
Moreover, when it comes to phrasal verbs themselves, a good range of them have a redundant particle. Fowler (1996: 594) notes that "one of the main objections raised to phrasal verbs is that they are used when the simple verb alone would suffice” (see also Beecher 2008 for a similar point). The examples below, quoted from Fowler (1996: 594), illustrate the redundancy of some phrasal verb combinations to the extent that the phrasal verb with or without the particle would be understood in the same way.

\begin{tabular}{|l||l|l|}
\hline \hline meet up with $=$ meet & lose out $=$ lose & miss out on $=$ miss \\
\hline \hline visit with = visit & rest up $=$ rest & drop off $=$ drop, fall \\
\hline \hline divide off/up = divide & measure off/out $=$ measure & select out $=$ select \\
\hline \hline
\end{tabular}

So here again there is a violation of Grice's maxims and mainly the Maxim of Quantity, which states that one should not say more than what is required:

1) Make your contribution as informative as is required

2) Do not make your contribution more informative than is required.

So, if I can say any of the phrasal verbs above without a particle and mean the same thing I am being redundant, and from a Gricean perspective, being intentionally redundant is not cooperative. Therefore, the unnecessary presence of a redundant particle makes the speaker's contribution more informative than is required, thereby violating the Gricean Maxim of Quantity.

The contrast between phrasal verbs used by native speakers in normal situations: as in a conversation and many other types of discourse and their use in cartoons could also be explained in terms of "marked” and "unmarked” concepts. A lot of words in language stand in binary opposition. For example, there is "old" and "young”; there is "tall” and "short"; there is "deep" and "shallow" etc. just as there are direct and indirect speech acts and literal and non-literal phrasal verbs. The choice of one or the other depends on which is appropriate in the given context of use. For example, when we ask people about their age or their height, we say "how old are you?" rather than "how young are you?” Even for babies’ age we ask how old they are. We also use "how tall rather than how short to ask for height. This is because “old”, “tall” and “deep” are unmarked 
(neutral), while their opposites are marked. They require a specific reason or context to be used. Obviously, there could always be a reason why we would do the reverse and ask how young or how short someone is. Context and other extra linguistic factors may determine which choice is appropriate. People can use "how young" to ask about age as in the following situation: "how young do people get married in X country?" Similarly, some speech acts may be issued directly and be considered normal like the use of some directives to children. Yet, if context requires that we be polite, we may have to formulate them indirectly. As for phrasal verbs that may be literal or non-literal, the tendency with those phrasal verbs above is to use them metaphorically; that is, as nonliteral. Yet, the context within which they were analyzed favors the literal interpretation; partly because of their contextual setting, the cartoons, and partly because humor is sought. An essential part of jokes, punning and humor in general is surprise. Markedness sometimes carries this aspect of surprise. So, I believe that the phrasal verbs above, as used in cartoons, may be considered as marked because of the humor and surprise they display.

\section{CONCLUSION}

Phrasal verbs used in cartoons represent a special class of verb particle construction in the sense that they have to be able to express at least two meanings, one literal and the other metaphorical or idiomatic. This is because cartoons play on the existence of a double context: a linguistic one, expressed verbally through the caption and a visual context represented through the image(s) or caricature used. Based on these two elements of context, which are usually in contrast, cartoonists draw the strings and send messages that create fun, humor and may even serve to criticize. This dichotomy of what is said and what is illustrated with its double message -one stated and one implied- gives room for the flouting of Grice's maxims, that of Quality in this case. We have suggested that phrasal verbs used in ordinary interactions are common and unmarked; whereas their special use in cartoons may be considered as marked because the purpose here is occasional and specific and aims at joking and humor in general. Additionally, there is a category of phrasal verbs, the particle of which can be redundant (see pg. 114 in this article for examples), and which in turn also flouts Grice's Maxim of 
Quantity. This type of phrasal verb did not appear in any of our cartoon examples but it is worth further investigating in a separate paper since although we may admit that the particle seems to be redundant, there must be a reason why it is used. In my view, the case of redundant phrasal verbs can better be explained in terms of the "marked/ unmarked" dichotomy. This point of redundant particles and (un)markedness is worth further investigation.

\section{REFERENCES}

Bannard, C., Baldwin, T. and Lascarides, A. 2003. "A statistical approach to the semantics of verb-particles”. In Proceedings of the ACL-2003 Workshop on Multiword Expressions: Analysis, Acquisition and Treatment, Japan, Sapporo, 6572.

Beecher, H. 2008. “Pragmatic licensing of redundant VPCs”. USCD. Linguistics Department. < $\underline{\text { www.docin.com/p-114154131.html }>}$

Biber, D., Johansson, S., Leech, G., Conrad, S., and Finnegan, E. 1999. Longman Grammar of Spoken and Written English. Harlow: Pearson Education Limited.

Bolinger, D. 1971. The Phrasal Verb in English. Harvard, USA: Harvard University.

Ceplair, L. 2008. “Linking up (combining) words: Phrasal verbs usage”. The Unpublished Manuscripts of Larry Ceplair. <www.larryceplair.com/ articles/ phrasals.php>

Claridge, C. 2000. Multi-Word Verbs in Early Modern English: A Corpus Based Study. Amsterdam/Atlanta: Rodopi.

Coulson, S. In press. "What's so funny: conceptual blending in humorous examples". In Herman, V. (Ed.) The Poetics of Cognition: Studies of Cognitive Linguistics and the Verbal Arts. Cambridge: Cambridge University Press. $<$ http://cogsci.ucsd.edu/\%7Ecoulson/funstuff/funny.html>

Fletcher, B. 2005. "Register and phrasal verbs". MED Magazine 33, Sept. $<$ http://www.macmillandictionary.com/MED-Magazine/September2005/33Phrasal-Verbs-Register.htm> 
Fowler, H.W. 1996. The New Fowler's Modern English Usage. $3^{\text {rd }}$ ed. R.W. Burchfield (Ed.). Oxford: Clarendon Press.

Frazer, B. 1976. The Verb-Particle Combination in English. New York: Academic Press.

Grice, P.H. 1975. “Logic and conversation”. In Cole, P. and J.L. Morgan (Eds.) Syntax and Semantics III: Speech Acts. New York: Academic Press, 41-58.

Kolln, M.J. and Funk R.W. 2008 Understanding English Grammar. Longman Publishing Group.

McArthur, T. Ed. 1992. The Oxford Companion to the English Language. Oxford/New York: Oxford University Press.

McCarthy, D., Keller, B. and Carroll, J. 2003. "Detecting a continuum of compositionality in phrasal verbs”. In Proceedings of the ACL-2003 Workshop on Multiword Expressions: Analysis, Acquisition and Treatment, Japan, Sapporo, 6572.

Patrick, J. and Fletcher, J. 2004. "Differentiating types of verb particle constructions”. In Proc. of Australasian Language Technology Workshop, 2004 (ALTW2004). <http://aclweb.org/anthology-new/U/U04/U04-1022.pdf>

Spasov, D. 1966. English Phrasal Verbs. Sofia, Bulgaria: Naouka Izkoustv.

Received: 17 October 2011

Accepted: 02 December 2011

Cite this article as:

Khir, A.N. 2012. “A semantic and pragmatic approach to verb particle constructions used in cartoons and puns”. Language Value 4 (1), 97-117. Jaume I University ePress: Castelló, Spain. http://www.e-revistes.uji.es/languagevalue. DOI: http://dx.doi.org/10.6035/LanguageV.2012.4.6

ISSN 1989-7103

Articles are copyrighted by their respective authors 